\title{
Uso do óleo essencial de capim santo como aditivo nutricional na dieta de juvenis de piau verdadeiro
} Use of capim santo essential oil as a nutritional additive in the diet of juvenile piau

\author{
SOUZA, Elizângela Maria de. Doutora em Zootecnia \\ IF Sertão-PE-Campus Petrolina Zona Rural. Rodovia BR 325, Km 22, Projeto Senador Nilo Coelho -N4- Petrolina-PE- \\ Brasil- CEP: 56300-00/ Telefone (87) 2101-8050/ E-mail: elizangela.maria@ifsertao-pe.edu.br
}

MACEDO, João Lucas Alves de. Discente do Bacharelado em Engenharia Elétrica UNIVASF - Campus Juazeiro-BA. Avenida Antônio Carlos Magalhães, 510, Santo Antônio - Juazeiro-BA- Brasil- CEP: 48902-300/ Telefone (74) 2102-7609/ E-mail: macedojlalves@gmail.com

LORENZO, Vitor Prates. Doutor em Produtos Naturais e Sintéticos Bioativos

IF Sertão-PE-Campus Petrolina Zona Rural. Rodovia BR 325, Km 22, Projeto Senador Nilo Coelho -N4- Petrolina-PEBrasil- CEP: 56300-00/ Telefone (87) 2101-8050/ E-mail: vitor.lorenzo@ifsertao-pe.edu.br

AMARAL, Daniel Ferreira. Mestre em Ecologia Humana e Gestão Sócio Ambiental IF Sertão-PE-Campus Petrolina Zona Rural. Rodovia BR 325, Km 22, Projeto Senador Nilo Coelho -N4- Petrolina-PEBrasil- CEP: 56300-00/ Telefone (87) 2101-8050/ E-mail: daniel.amaral@ifsertao-pe.edu.br

VALÉRIO, Carla Samantha Rodrigues Silva. Mestre em Ciência Animal

IF Sertão-PE-Campus Petrolina Zona Rural. Rodovia BR 325, Km 22, Projeto Senador Nilo Coelho -N4- Petrolina-PEBrasil- CEP: 56300-00/ Telefone (87) 2101-8050/ E-mail: carla.samantha@ifsertao-pe.edu.br

JESUS, Fábio Nascimento. Doutor em Ciências Agrárias

IF Sertão-PE-Campus Petrolina Zona Rural. Rodovia BR 325, Km 22, Projeto Senador Nilo Coelho -N4- Petrolina-PEBrasil- CEP: 56300-00/ Telefone (87) 2101-8050/ E-mail: fabio.nascimento@ifsertao-pe.edu.br

\section{RESUMO}

Este estudo teve como objetivo avaliar o efeito do óleo essencial de capim santo Cymbopogon citratus sobre o desempenho de juvenis de piau verdadeiro quando adicionado à dieta. $\mathrm{O}$ experimento foi conduzido no Laboratório de Piscicultura, em delineamento experimental inteiramente casualizado, com quatros tratamentos (dietas com níveis crescentes do óleo essencial: 0; 0,5; 1,0 e 1,5 mL/ kg em ração comercial) e sete repetições. 0 óleo essencial de capim santo foi diluído em álcool de cereal e pulverizado a ração comercial. Os peixes foram distribuídos em 28 caixas de $100 \mathrm{~L}$, alimentados duas vezes ao dia. Ao término avaliou-se parâmetros zootécnicos: ganho de peso médio, taxa de crescimento específico e sobrevivência. Não houve diferença significativa entre os tratamentos, para os parâmetros: ganho de peso e taxa de crescimento específico, porém, a inclusão de $0,5 \mathrm{~mL} / \mathrm{kg}$ (T2) promoveu de $100 \%$ de sobrevivência.

Palavras-chave: fitoaditivo, peixe nativo, ração

\section{ABSTRACT}

This study aimed to evaluate the effect of the essential oil of capim santo Cymbopogon citratus on the performance of juveniles of true piau when added to the diet. The experiment was carried out at the Pisciculture Laboratory, in a completely randomized design, with four treatments (diets with increasing levels of essential oil: $0 ; 0.5 ; 1.0$ and $1.5 \mathrm{~mL} / \mathrm{kg}$ in commercial feed) and seven replications. The essential oil of capim santo was diluted with cereal alcohol and sprayed with commercial feed. The fish were distributed in 28 boxes of $100 \mathrm{~L}$, fed twice a day. At the end, zootechnical parameters were evaluated: average weight gain, specific growth rate and survival. There was no significant difference between treatments, for the parameters: weight gain and specific growth rate, however, the inclusion of $0.5 \mathrm{~mL} / \mathrm{kg}(\mathrm{T} 2)$ promoted $100 \%$ survival. 
Key-words: fitoaditive, native fish, feed

\section{Introdução}

Nos últimos anos, os avanços na nutrição têm tido um papel de grande relevância dentro da cadeia produtiva de peixes, estando cada vez mais relacionado com a saúde humana, a biossegurança e preservação do meio ambiente.

O uso de óleos essenciais obtidos a partir de diversas partes das plantas, como folhas, flores, sementes, brotos, frutos ou mesmo da planta inteira, tem sido usado como promotores de crescimento e aumento da imunidade em peixes (ZEPPENFELD et al., 2015).

A utilização de óleos essenciais como aditivos (fitoaditivos) na alimentação de peixes tem mostrado resultados positivos tanto para o desempenho animal quanto para saúde humana e ambiental, por serem biodegradáveis e de rápida metabolização no organismo animal, com baixo risco de acúmulo nos tecidos, são absorvidos no intestino e rapidamente metabolizados no organismo (VALLADÃO et al., 2015; BANDEIRA JÚNIOR et al., 2017).

O principal mecanismo de ação dos promotores de crescimento a base de extratos vegetais, está relacionado ao aumento da: atividade das enzimas e absorção dos nutrientes, maior aproveitamento de macronutrientes, estimulação do apetite, eficiência alimentar, imunidade, além de diminuírem o estresse em peixes (BALDISSEROTTO et al., 2017).

Um dos principais objetivos da piscicultura é a melhoria do desempenho produtivo de peixes. A adição de óleos essenciais na dieta de peixes tem sido amplamente relatada, mostrando melhora no desempenho zootécnico, resposta imune e resistência bacteriana. Neste sentido, alguns estudos têm demonstrado o potencial de óleo essencial na alimentação de peixes (ZHENG et al., 2009; VALLADÃO et al., 2015; SOUZA et al., 2020).

Considerando as propriedades farmacológicas dos óleos essenciais, é necessário que se desenvolvam estudos direcionados aos seus efeitos como aditivos na dieta, de forma que proporcionem melhoria no desempenho, no bem-estar dos peixes. Estudos sobre o uso do óleo essencial de $C$. citratus como aditivo nutricional em peixes ainda não foi relatado na literatura. Dessa forma, o presente estudo objetivou avaliar o 
efeito do óleo essencial de capim santo (C. citratus) sobre o desempenho de juvenis de piau verdadeiro quando adicionado à dieta.

\section{Referencial teórico}

\section{Óleos essenciais}

Os óleos essenciais, podem ser chamados de óleos voláteis ou etéreos, as quais são atribuídas em função de suas características físico-químicas. São substâncias líquidas, lipofílicas, complexas, bioativas, voláteis, com odor e cor característicos, formados a partir de metabólitos secundários. A grande maioria dos óleos essenciais é constituída de derivados de terpenóides ou de fenilpropanóides, indol e compostos sulfurados (BAKALLI et al., 2008; BERALDO et al., 2013; SHARMA et al., 2013; ANDRADE et al., 2014; MAZZARRINO et al., 2015; SOUZA et al., 2018). A composição química (quantitativa e qualitativa) de um óleo essencial podem ser modificadas por vários aspectos, como: modo de extração, fatores intrínsecos da planta (ex. idade, espécie ou cultivar) (SILVA et al., 2011), condições ambientais de cultivo e coleta (ex.: época, forma) e presença de agentes patogênicos e insetos (GOBBO-NETO; LOPES, 2007).

Os óleos essenciais podem estar presentes em certos órgãos, tais como nas flores, folhas ou ainda nas cascas dos caules, madeira, raízes, rizomas, frutos ou sementes. São utilizados inúmeros métodos para a extração de óleo essencial, e estes variam de acordo com a localização do óleo na planta, da quantidade e da proposta de utilização do mesmo. Os processos mais comuns de extração dos óleos essenciais são: enfloração, hidrodestilação, expressão de pericarpo de frutos cítricos, enfleurage, arraste por vapor d'água, com solventes orgânicos e prensagem (SEMEN; HIZIROGLU, 2005; SIMÕES et al., 2007).

\section{Capim santo (C.citratus)}

Cymbopogon citratus (Figura 1) é uma gramínea perene, originária da Índia, e encontrada difundida em vários países, e aclimatada nas regiões tropicais do Brasil, conhecida popularmente como capim-limão, capim-santo, capim-cidró, capimcheiroso, capim-cidreira, capim-cidrão, citronela-de-java e erva-cidreira (SANTOS et al., 2009). Esta espécie é cultivada para a produção comercial de óleo essencial em praticamente em todos os países tropicais, sendo empregado nas indústrias 
famacêuticas e de cosméticos.

Pertencente à família das Poaceae, é uma planta aromática cultivada para produção comercial de óleo essencial, denominado internacionalmente como "lemongrass", o qual geralmente apresenta como constituintes majoritários os monoterpenos citral (mistura isomérica de neral e geranial) e o mirceno, sendo o citral que é citado na maioria dos efeitos terapêuticos (PRINS et al., 2008; FURLAN et al., 2010; PEREIRA; PAULA, 2018).

Figura 1 - Capim limão do Horto Medicinal do Campus Petrolina Zona Rural

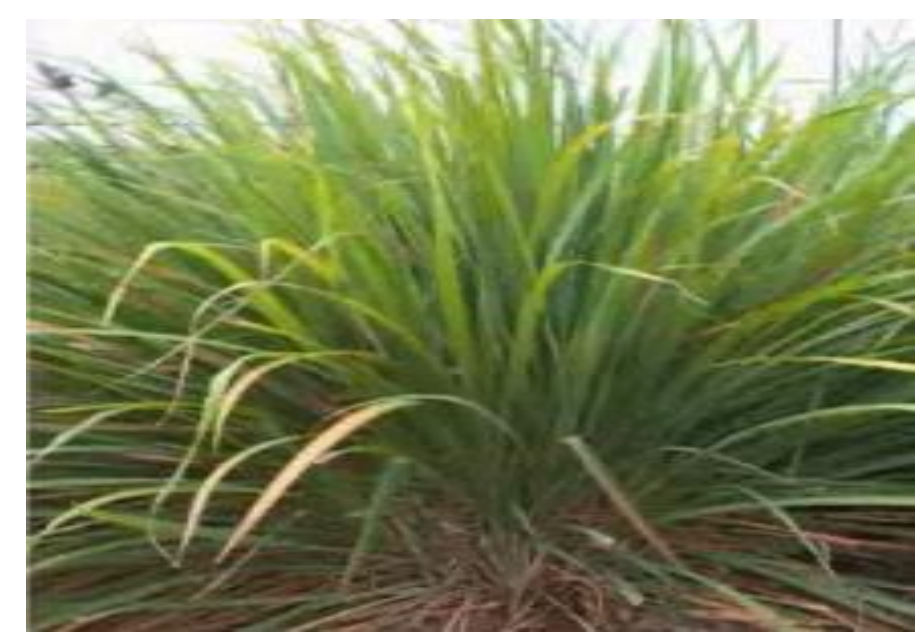

Fonte: arquivo do horto medicinal (CPZR)

O C.citratus tem proriedades como sedativo, sudorífero, febrífugo, diurético, antipirético, antireumático, anestésico, analgésico, anticarcinogênica, antibacteriana, antihelmítica, antifúngica, inseticida e larvicida, que são atribuídas ao citral e mirceno de seu óleo essencial (LORENZI; MATOS, 2002; OLIVEIRA et al., 2011).

Na piscicultura a complementação dietética e/ou adição do citral na água pode ser benéfica tanto para melhorar as condiçoes de saúde, como para a prevenção de doenças, levando o aumento da produtividade e beneficiamento no cultivo de peixes.

\section{Piau verdadeiro (Leporinus obtusidens)}

O L. obtusidens (Figura 2) é uma espécie nativa do rio São Francisco pertence a ordem Characiforme e família Anastomidae, sendo conhecido popularmente por piapara, piau-verdadeiro ou simplesmente piau, tendo ocorrência nas bacias dos rios Prata, Paraná e São Francisco. Esta espécie foi resentemente reclassificada 
taxonomicamente para a bacia do rio São Francisco, sendo agora definida como $L$. obtusidens, embora anteriormente fosse classificada como L. elongatus (BRITSKI et al., 2012).

Figura 2 - Exemplar de piau Leporinus obtusidens.

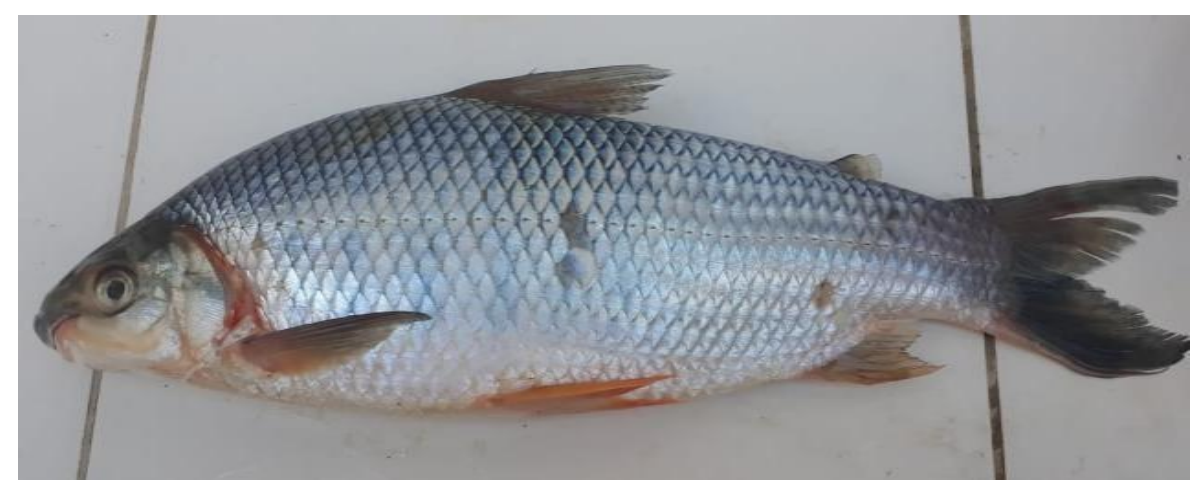

Fonte: Amaral (2017)

O L.obtusidens tem hábito alimentar onívoro que se alimenta principalmente de sementes, insetos aquáticos, crustáceos e moluscos, alguns autores classificam este peixe como onívoro de amplo espectro, o que, do ponto de vista da nutrição, proporciona vantagem no aproveitamento dos alimentos (TAITSON et al., 2008).

O piau verdadeiro é um peixe migrador (de piracema), subindo os rios até locais com condições físico-químicas adequadas para a desova, entre os meses de dezembro e janeiro (VAZZOLER, 1996). É uma espécie de grande importância comercial, na no Vale do São Francisco, sendo encontrado em mercados e feiras livres (CAMPECHE et al., 2011).

\section{Material e métodos}

O experimento foi aprovado pela Comissão de Ética no Uso de Animais (CEUA) do Instituto Federal do Sertão Pernambucano, conforme parecer $n^{\circ}$ 031/2017.

\section{Extração do óleo essencial}

As plantas de C. citratus foram cultivadas no Horto Medicinal do IF Sertão-PE Campus Petrolina Zona Rural. A extração do óleo essencial ocorreu Laboratório de Química do Campus Petrolina Zona Rural a partir de folhas frescas da planta por hidrodestilação usando o método de Clevenger. Foram utilizados $600 \mathrm{~g}$ de folhas de capim limão para obtenção de $3 \mathrm{~mL}$ de óleo essencial. A composição química do óleo 
essencial do presente trabalho foi realizada por Carvalho et al. (2018) através de cromatografia gasosa.

\section{Experimento in vivo}

O experimento in vivo teve duração de 40 dias e foi conduzido no Laboratório de Piscicultura do IF Sertão-PE Campus Petrolina Zona Rural, em delineamento experimental inteiramente casualizado, com quatros tratamentos e sete repetições. Foram utilizados 28 peixes, todos provenientes do Centro Integrado de Recursos Pesqueiros e Aquicultura de Bebedouro - $3^{\text {a }}$ Superintendência Regional da CODEVASF (Companhia de Desenvolvimento dos Vales do São Francisco e do Parnaíba).

Os peixes foram aclimatados por um período de dez dias. Foram avaliadas quatro dietas com níveis crescentes do óleo essencial de capim santo $(0 ; 0,50 ; 1,0$ e $1,5 \mathrm{~mL} / \mathrm{kg}$ ) em ração extrusada comercial com 32\% de proteína bruta. O óleo essencial de capim santo foi adicionado a ração através da técnica de pulverização (Figura 3). Utilizou-se $100 \mathrm{~mL}$ de álcool de cereal como diluente do óleo essencial, após diluição foram colocados em quatro pulverizadores plásticos e aplicados de forma homogênea à ração. Os peixes com média de $27 \mathrm{~g}$ foram distribuídos em 28 caixas de $100 \mathrm{~L}$ (um peixe por caixa), com aeração constante.

A limpeza das caixas foi feita uma vez ao dia por meio de um sifonamento de $25 \%$ da água das caixas para a retirada das fezes e eventuais sobras de ração. As variáveis físico- químicas da água $\mathrm{pH}$ (kit labtest), temperatura (termômetro digital Incoterm) e oxigênio dissolvido (kit labtest), foram monitoradas diariamente e a amônia total (kit labtest) semanalmente.

Figura 3 - Aplicação do óleo essencial de capim santo em ração comercial através da técnica de pulverização. 


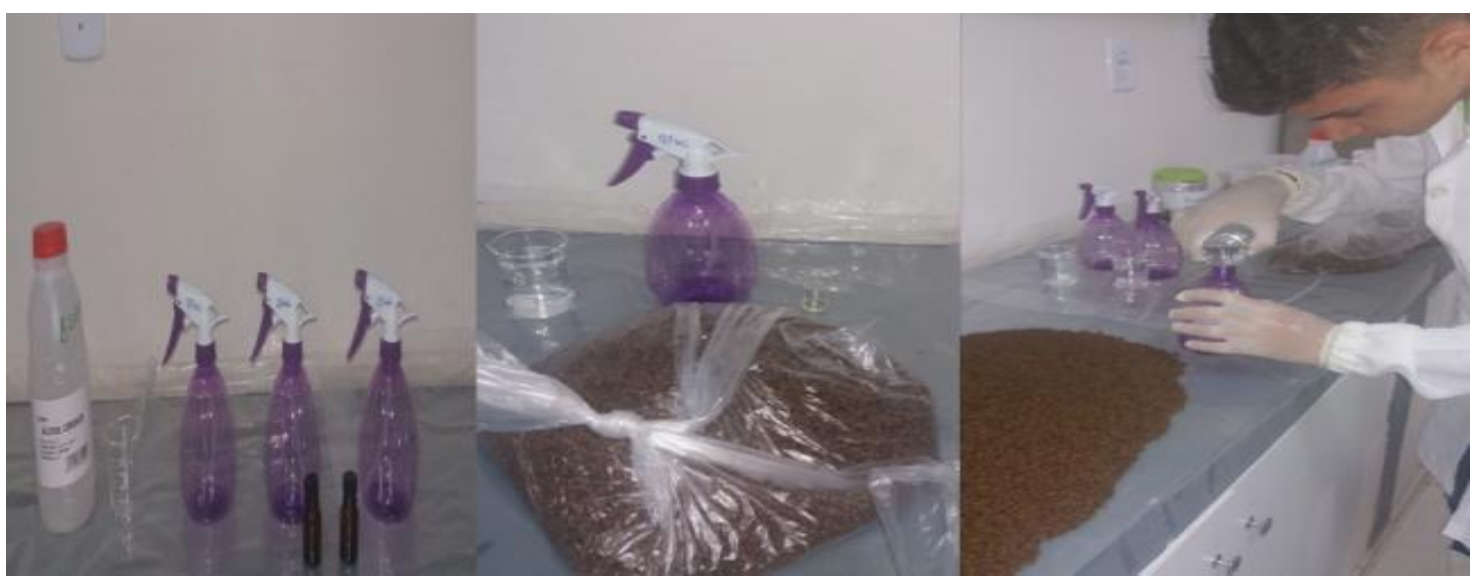

Fonte: (SOUZA, 2017)

\section{Parâmetros Zootécnicos}

Os peixes foram alimentados duas vezes ao dia durante todo período experimental, e ao término foram avaliadas variáveis de desempenho zootécnico: ganho de peso médio, taxa de crescimento específico e sobrevivência, calculadas de acordo com as equações abaixo.

GPM = Peso final (g) - Peso inicial (g);

TCE $=100 \times$ (ln Peso final - ln Peso inicial)/tempo de duração do experimento (dias). In = logaritmo neperiano;

$S(\%)=[($ Número total de peixe final/número total de peixes inicial $) \times 100]$.

\section{Estatística}

O delineamento experimental foi DIC, com quatro tratamentos e sete repetições. Todos os dados foram expressos em média \pm erro padrão. Os dados foram avaliados por análise de variância (ANOVA) e teste de Tukey a 5\% de probabilidade (programa estatístico Sisvar).

\section{Resultados e Discussão}

Um dos principais objetivos da piscicultura é a melhoria do desempenho produtivo de peixes. A adição de óleos essenciais na dieta de peixes tem sido amplamente relatada, mostrando melhora no desempenho zootécnico, resposta imune e resistência bacteriana (ACAR et al., 2015; BANDEIRA JÚNIOR et al., 2017).

A inclusão o óleo essencial de $C$. citratus como aditivo nutricional na dieta de juvenis de piau verdadeiro, não promoveu diferença significativa nos aspectos 
zootécnicos: ganho de peso médio (GPM) e na taxa de crescimento específico (TCE) (Tabela 1). No parâmetro zootécnico referente a sobrevivência (Tabela 1) ocorreu diferença significativa entre os tratamentos, a inclusão de $0,5 \mathrm{~mL} / \mathrm{Kg}$ (T2) foi de $100 \%$, enquanto o maior nível de inclusão de $1,5 \mathrm{~mL} / \mathrm{kg}$ (T4) reduziu a taxa de sobrevivência a $60 \%$. Os tratamentos T1 $(0,0 \mathrm{~mL} / \mathrm{kg})$ e T3 $(1,0 \mathrm{~mL} / \mathrm{kg})$ não diferiram entre eles.

Tabela 1 - Desenvolvimento de juvenis de piau verdadeiro (L. obtusidens) alimentados com dietas contendo diferentes concentrações de óleo essencial de capim santo ( $C$. citratus) durante 40 dias. GPM = Ganho de Peso Médio; TCE = Taxa de Crescimento Específico; S (Sobrevivência).

\begin{tabular}{cccc}
\hline $\begin{array}{c}\text { Óleo essencial de } \\
\text { capim santo } \\
\text { (C. citratus) }\end{array}$ & $\begin{array}{c}\text { GPM } \\
\mathbf{( g )}\end{array}$ & $\begin{array}{c}\text { TCE } \\
(\%)\end{array}$ & $\begin{array}{c}\text { S } \\
(\%)\end{array}$ \\
\hline T1 $(0,0 \mathrm{~mL} / \mathrm{kg})$ & $4,42^{\mathrm{a}}$ & $0,42^{\mathrm{a}}$ & $80^{\mathrm{b}}$ \\
T2 $(0,5 \mathrm{~mL} / \mathrm{kg})$ & $6,34^{\mathrm{a}}$ & $0,64^{\mathrm{a}}$ & $80^{\mathrm{b}}$ \\
T3 $(1,0 \mathrm{~mL} / \mathrm{kg})$ & 6,64 & $0,62^{\mathrm{a}}$ & $100^{\mathrm{a}}$ \\
T4 $(1,5 \mathrm{~mL} / \mathrm{kg})$ & $6,48^{\mathrm{a}}$ & $0,73^{\mathrm{a}}$ & $60^{\mathrm{c}}$ \\
\hline CV $(\%)^{*}$ & 64,02 & 59,80 & 0,00 \\
\hline${ }^{*} \mathrm{CV}=$ coeficiente de variação & Fonte: pesquisa direta.
\end{tabular}

O óleo essencial deste estudo apresenta elevadas concentrações de myrcene $(12,65 \%)$, citral (neral: $31,89 \%)$, geronial $(2,6$-octodienal,3,7-dimenthyl-,(E) $(41,65 \%)$ (CARVALHO et al., 2018).

Os resultados observados referentes a ganho de peso e a taxa de crescimento, não corroboram com estudos prévios feitos com adição de outros óleos essenciais à dieta, e que tinham como principal componente majoritário, o citral. A inclusão de 2,0 mL/kg de óleo essencial de Aloysia triphylla na dieta de jundiá promoveu maior ganho de peso nos animais alimentados (ZEPPENFELD et al., 2015). A suplementação de $2 \mathrm{~mL} / \mathrm{kg}$ de óleo essencial de $A$. triphylla na dieta de juvenis de tilápia do Nilo apresentou-se como promissor promotor de crescimento e imunoestimulante (SOUZA et al., 2020). Tilápias do Nilo alimentadas com dietas contendo 1,0 a 2,0 mL/kg do óleo essencial de Cymbopogon flexuosus, promoveram o aumento no ganho de peso e taxa de crescimento (SOUZA et al., 2019). 
Durante todo o período as variáveis apresentaram-se dentro dos valores exigidos para piau verdadeiro: temperatura $\left(25,8 \pm 0,14^{\circ} \mathrm{C}\right), \mathrm{pH}(6,7 \pm 0,22)$, oxigênio dissolvido $(5,7 \pm 0,18 \mathrm{mg} \mathrm{OD} / \mathrm{L})$ e amônia total $(0,05 \pm 0,01 \mathrm{mg} \mathrm{NH} / \mathrm{L})$.

\section{Conclusões}

Considerando as propriedades dos óleos essenciais, é necessário que se desenvolvam estudos direcionados, principalmente no que se refere à adição desses compostos na alimentação de peixes, procurando estabelecer uma concentração na dieta, que proporcione o melhor desempenho e o aumento da taxa de sobrevivência.

A utilização de óleos essenciais e extratos como aditivos para alimentação dos peixes tem demonstrado grande potencial, necessitando ainda que ensaios in vivo sejam realizados para se determinar a utilização definitiva destes compostos.

Agradecimentos: Ao IF Sertão-PE pela oportunidade do projeto e da bolsa concedida. A Prof. ${ }^{a}$ Flávia Cartaxo por disponibilizar as plantas (capim limão) do Horto Medicinal para realização do experimento e o resultado da análise cromatográfica do óleo essencial. A Eliatânia por auxiliar na extração do óleo essencial no Laboratório de Química do Campus Petrolina Zona Rural.

\section{Referências}

ACAR, U.; KESBIÇ, O.S.; SEVDAN YILMAZ, S.; GÜLTEPE, N.; ALI TÜRKER,A. Evaluation of the effects of essential oil extracted fromsweet orange peel (Citrus sinensis) on growth rate of tilapia (Oreochromis mossambicus) and possible disease resistance against Streptococcus iniae. Aquaculture, v.437, p.282-286, 2015.

ANDRADE, B. F. M. T.; BARBOSA, L. N.; PROBST, I.S.;FERNANDES JUNIOR, A. Antimicrobial activity of essential oils. Journal of Essential Oil Research, v.1, p. 3440, 2014.

BAKALLI, F; AVERBECK ,S; AVERBECK, D; IDAOMAR, M. Biological effects of essential oils: a review. Food and Chemical Toxicology, v. 46, p.446-475, 2008.

BALDISSERROTO, B.; GOMES, L.C.; HEINZMANN, B.M,; CUNHA, M.A. Farmacologia aplicada à aquicultura. Santa Mari, RS: Ed. UFMS, 656 p., 2017.

BANDEIRA JR, G.; PÊS, T.S.; SACCOL, E.M.H.; SUTILI, F.J.; ROSSI JR, W.R.; MURARI, 
A.L.; HEINZMANN, B.M.; PAVANATO, M.A.; VARGAS, A.C.; SILVA, L.L.; BALDISSEROTTO, B. Potential uses of Ocimum gratissimum and Hesperozygis ringens essential oils in aquaculture. Industrial Crops and Products, v.97, p.484-491, 2017.

BERALDO, C.; DANELUZZI, N.S.; SCANAVACCA, J.; DOYAMA, J.T.; FERNANDES JÚNIOR, A.; FENIMAN, C.M. Eficiência de óleos essenciais de canela e cravo-da-índia como sanitizantes na indústria de alimentos. Pesquisa Agropecuária Tropical, v.43, p. 436440, 2013.

BRITSKI, H.A.; BIRINDELLI, J.L.O.; GARAVELLO, J.C. A new species of Leporinus Agassiz, 1829 from the upper Rio Paraná basin (Characiformes, Anostomidae) with redescription of L. elongatus Valenciennes, 1850 and L. obtusidens (Valenciennes, 1837). Papéis Avulsos da Zoologia, Volume v. 52, p.441-475, 2012.

CAMPECHE, D.F.B.; BALZANA, L.; FIGUEIREDO, R.C.R.; BARBALHO, M.R.S.; REIS, F.J.S.; MELO, J. F.B. Peixes nativos do Rio São Francisco adaptados para cultivo. Petrolina: Embrapa Semiárido, 20 p., 2011.

CARVALHO, I.R.; CARDOSO, A.C.; VILAR, F.R.C.; PRATES, V.L.; RAMALHO, R.C.; DANTAS, F.H.A.; GOMES, L.N. Composição química do óleo essencial de Cymbopogon citratus (capim santo) cultivada com as práticas agroecológicas no perímetro irrigado de Petrolina/PE. Anais do Congresso Internacional Interdisciplinar em Extensão Rural e Desenvolvimento - CIIERD, 2018.

FURLAN, M.R.; MARTINS, R.C.C.; RODRIGUES, E. SCALCO, N.; NEGRI, G.; LAGO, J.H.G. Variação dos teores de constituintes voláteis de Cymbopogon citratus (DC) Staf, Poaceae, coletados em diferentes regiões do Estado de São Paulo. Revista Brasileira de Farmacognosia v.20, p. 686- 691, 2010.

GOBBO-NETO, L.; LOPES, N.P. Plantas medicinais: fatores de influência no conteúdo de metabólitos secundários. Química Nova, v.30, p.374381, 2007.

LORENZI, H; MATOS, F. J. A.; Plantas medicinais no Brasil, nativas e exóticas. São Paulo: Instituto Plantarum de Estudos da Flora LTDA, 2002.

MAZZARRINO, G.; PAPARELLA, A.; CHAVES-LÓPEZ, C.; FABERI, A.; SERGI, M.; SIGISMONDI, C.; COMPAGNONE, D.; SERIO, A. Salmonella enterica and Listeria monocytogenes inactivation dynamics after treatment with selected essential oils. Food Control, v. 50, p. 794-803, 2015.

OLIVEIRA, M.M.M.; BRUGNERA, D.F.; CARDOSO, M.G.; GUIMARÃES, L.G.L.; PICCOLI, R.H. Rendimento, composição química e atividade antilisterial de óleos essenciais de espécies de Cymbopogon. Revista Brasileira de Plantas Medicinais, Botucatu, v.13, p.8-16, 2011.

OUSSALAH, M.; CAILLET, S.; SAUCIER, L.; LACROIX, M. Inhibitory effects of selected plant essential oils on the growth of four pathogenic bacteria: E. coli 0157:H7, Salmonella typhimurium, Spaphylococcus aureus e Listerria monocytogenes. Food 
Control, 2006.

PEREIRA, P.S.; PAULA, L.L.R.J. Ações terapêuticas do capim-santo: uma revisão de literatura therapeutic actions of grass-saint: a literature review. Revista Saúde em Foco, v.10, p.259-263, 2018.

PRINS, C. L. et al. Efeitos de confinamento do sistema radicular sobre capim-limão (Cymbopogon citratus). Revista Ciência Agronômica, v. 39, n. 03, p. 416-421, 2008.

SANTOS, A.; PADUAN, R.H.; GAZIN, Z.C.; JACOMASSI, E.; D’OLIVEIRA, P.S.; CORTEZ, D.A.G.; CORTEZ, L.E.R. Determinação do rendimento e atividade antimicrobiana do óleo essencial de Cymbopogon citratus (DC.) Stapf em função de sazonalidade e consorciamento. Revista Brasileira de Farmacognosia; v. 19, p. 436-441, 2009.

SEMEN, E.; HIZIROGLU. Production, yield and Derivatives of Volatile Oils from Eastern Redcedar (Jeniperus virgiana L.), American Journal Environmental Sciences, 1(2), p. 133-138, 2005.

SHARMA, R. et al. Fish Proteins in Coronary Artery Disease Prevention Amino Acid-Fatty Acid Concept. In: WATSON, R. R. e PREEDY, V. R. (Ed.). Bioactive Food as Dietary Interventions for Cardiovascular Disease. USA: Elsevier, cap. 32, p.525-549, 2013.

SILVA, F. FERREIRA, S. QUEIROZ, J.A.; DOMINGUES, F.C. Coriander (Coriandrum sativum L.) essential oil: its antibacterial activity and mode of action evaluated by flow cytometry. Journal of Medical Microbiology, v.60, p.1479-1486, 2011.

SIMÕES, C. M. O.; SCHENKEL, E. P.; GOSMANN, G.; MELLO, J. C. P.; MENTZ, L. A.; PETROVICK, P. R. Farmacognosia: da planta ao medicamento. Ed. 6a, Porto Alegre, ED. UFRGS, 1102 p., 2007.

SOUZA, E.M.; SOUZA, R.C.; COSTA, M.M.;PINHEIRO, C.G.; HEINZMANN, B.M. COPATTI, C.E. Chemical composition and evaluation of the antimicrobial activity of two essential oils. Boletim do Instituto de Pesca, v.44, p.1-4, 2018.

SOUZA, E.M.; SOUZA, R.C.; MELO, J.B.M.; COSTA, M.M.; SOUZA, A.M.;COPATTI, C.E. Evaluation of the effects of Ocimum basilicum essential oil in Nile tilapia diet:growth, biochemical, intestinal enzymes, haematology, lysozyme and antimicrobial challenges. Aquaculture, v.504, p.7-12, 2019.

SOUZA, R.C.; BALDISSEROTTO, B.; MELO, J.F.B.; COSTA, M.M.; SOUZA, E.M.; COPATTI, C.E. Dietary Aloysia triphylla essential oil on growth performance and biochemical and haematological variables in Nile tilapia. Aquaculture, v. 519, p. 1-7, 2020.

TAITSON, P.F.; CHAMI, E.; GODINHO, H.P. Gene banking of the neotropical fish Leporinus obtusidens (Valenciennes, 1836): A protocol to freeze its sperm in the field. Animal Reproduction Science, v.105, p. 283-291, 2008.

VALLADÃO, G.M.R.; GALLANI, S.U.; PILARSKI, F. Phytotherapy as an alternative for treating fish disease. Journal of Veterinary Pharmacology and 
Therapeutics, v. 38, p. 417-428, 2015.

VAZZOLER, A.E.A.M. Biologia da reprodução de peixes teleósteos : teoria e prática. Maringá : EDUEM ; São Paulo : SBI, 1996. 169 p. : il.

ZHENG, Z.L.; TAN, J.Y.W.; LIU, H.Y.; ZHOU, X.H.; XIANG, X.; WANG, K.Y. Evaluation of oregano essential oil (Origanum heracleoticum L.) on growth, antioxidant effect and resistance against Aeromonas hydrophila in channel catfish (Ictalurus punctatus). Aquaculture, p.214-218, 2009.

ZEPPENFELD, C. C.; HERNÁNDEZ, D. R.; SANTINÓN, J. J.; HEINZMANN, B. M.; DA CUNHA, M. A.; SCHMIDT, D.; BALDISSEROTTO, B. Essential oil of Aloysia triphylla as feed additive promotes growth of silver catfish (Rhamdia quelen). Aquaculture Nutrition, v. 22, p. 933-940, 2015. 